NASA/TM-2005-213434

\title{
Atomic Oxygen Treatment and Its Effect on a Variety of Artist's Media
}

Sharon K.R. Miller and Bruce A. Banks

Glenn Research Center, Cleveland, Ohio

Deborah L. Waters

QSS Group, Inc., Cleveland, Ohio 
Since its founding, NASA has been dedicated to the advancement of aeronautics and space science. The NASA Scientific and Technical Information (STI) Program Office plays a key part in helping NASA maintain this important role.

The NASA STI Program Office is operated by Langley Research Center, the Lead Center for NASA's scientific and technical information. The NASA STI Program Office provides access to the NASA STI Database, the largest collection of aeronautical and space science STI in the world. The Program Office is also NASA's institutional mechanism for disseminating the results of its research and development activities. These results are published by NASA in the NASA STI Report Series, which includes the following report types:

- $\quad$ TECHNICAL PUBLICATION. Reports of completed research or a major significant phase of research that present the results of NASA programs and include extensive data or theoretical analysis. Includes compilations of significant scientific and technical data and information deemed to be of continuing reference value. NASA's counterpart of peerreviewed formal professional papers but has less stringent limitations on manuscript length and extent of graphic presentations.

- TECHNICAL MEMORANDUM. Scientific and technical findings that are preliminary or of specialized interest, e.g., quick release reports, working papers, and bibliographies that contain minimal annotation. Does not contain extensive analysis.

- CONTRACTOR REPORT. Scientific and technical findings by NASA-sponsored contractors and grantees.
- CONFERENCE PUBLICATION. Collected papers from scientific and technical conferences, symposia, seminars, or other meetings sponsored or cosponsored by NASA.

- SPECIAL PUBLICATION. Scientific, technical, or historical information from NASA programs, projects, and missions, often concerned with subjects having substantial public interest.

- TECHNICAL TRANSLATION. Englishlanguage translations of foreign scientific and technical material pertinent to NASA's mission.

Specialized services that complement the STI Program Office's diverse offerings include creating custom thesauri, building customized databases, organizing and publishing research results ... even providing videos.

For more information about the NASA STI Program Office, see the following:

- Access the NASA STI Program Home Page at http://www.sti.nasa.gov

- E-mail your question via the Internet to help@sti.nasa.gov

- Fax your question to the NASA Access Help Desk at 301-621-0134

- Telephone the NASA Access Help Desk at 301-621-0390

- Write to:

NASA Access Help Desk

NASA Center for AeroSpace Information 7121 Standard Drive

Hanover, MD 21076 
NASA/TM-2005-213434

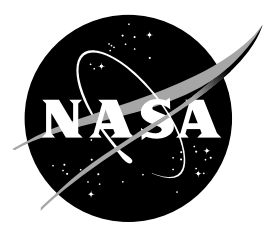

\section{Atomic Oxygen Treatment and Its Effect on a Variety of Artist's Media}

Sharon K.R. Miller and Bruce A. Banks

Glenn Research Center, Cleveland, Ohio

Deborah L. Waters

QSS Group, Inc., Cleveland, Ohio

Prepared for the

2004 Fall Meeting

sponsored by the Materials Research Society

Boston, Massachusetts, November 29-December 3, 2004

National Aeronautics and

Space Administration

Glenn Research Center 


\section{Acknowledgments}

The authors would like to thank Bruce Christman and Kenneth Bé of the Cleveland Museum of Art, Father Bob Weaver and the members of St. Alban's Episcopal Church, Deborah Grale and the members of St. Stanislaus Church, Jia-sun Tsang of the Smithsonian Institution (SCRME), Richard Moore of Bonfoey Company, and William Real of the Carnegie Museum of Art for providing media for testing and for their helpful comments, suggestions and advice.

Trade names or manufacturers' names are used in this report for identification only. This usage does not constitute an official endorsement, either expressed or implied, by the National Aeronautics and Space Administration.

Available from

NASA Center for Aerospace Information 7121 Standard Drive

Hanover, MD 21076
National Technical Information Service 5285 Port Royal Road Springfield, VA 22100 


\title{
Atomic Oxygen Treatment and Its Effect on a Variety of Artist's Media
}

\author{
Sharon K.R. Miller and Bruce A. Banks \\ National Aeronautics and Space Administration \\ Glenn Research Center \\ Cleveland, Ohio 44135 \\ Deborah L. Waters \\ QSS Group, Inc. \\ Cleveland, Ohio 44135
}

\begin{abstract}
Atomic oxygen treatment has been investigated as an unconventional option for art restoration where conventional methods have not been effective. Exposure of surfaces to atomic oxygen was first performed to investigate the durability of materials in the low Earth orbit environment of space. The use of the ground based environmental simulation chambers, developed for atomic oxygen exposure testing, has been investigated in collaboration with conservators at a variety of institutions, as a method to clean the surfaces of works of art. The atomic oxygen treatment technique has been evaluated as a method to remove soot and char from the surface of oil paint (both varnished and unvarnished), watercolors, acrylic paint, and fabric as well as the removal of graffiti and other marks from surfaces which are too porous to lend themselves to conventional solvent removal techniques. This paper will discuss the treatment of these surfaces giving an example of each and a discussion of the treatment results.
\end{abstract}

\section{Introduction}

Fire in any structure housing an art collection, or the deliberate or accidental addition of marks can result in great cultural loss if the art is not recoverable. Charred paint binder, soot on surfaces difficult to clean using solvents, and graffiti on porous surfaces all present a challenge for restoration by conventional methods. At the request of and in collaboration with many conservators representing museums and private studios worldwide, the use of atomic oxygen as a treatment technique has been investigated for damage not removable by conventional methods.

Atomic oxygen is present in the atmosphere surrounding the Earth at altitudes where satellites typically orbit and is chemically reactive with surfaces or deposits that contain carbon $[1,2]$. The reaction converts the carbon to volatile species such as carbon monoxide. Ground based facilities, developed for durability testing of satellite materials to atomic oxygen, dissociate molecular oxygen into atomic oxygen by radio frequency (RF) electric fields, microwave radiation or electron bombardment, typically under a partial vacuum between 0.027 and $20 \mathrm{~Pa}\left(2 \times 10^{-4}\right.$ to 0.15 torr $)$ depending on the process $[3,4]$. For the atomic oxygen treatment discussed in this paper, both large and small area RF facilities were used to remove soot and char as described in references 5 and 6, while spot cleaning and removal of graffiti and marks were performed using a DC arc device operated at atmospheric pressure as described in reference 7.

Atomic oxygen is of interest for cleaning fine art because there is no mechanical contact with the surface, many pigments which are composed of metal oxides are not affected by the 
process, and the reaction is confined to the surface, which reduces the risk of damage to the underlying surface. This paper describes the results of using atomic oxygen treatment on a variety of artist's media. The process, which has been patented by NASA, is not intended to be a replacement for conventional restoration techniques, but to be an additional tool for use where conventional techniques may not be effective [8].

\section{Discussion and Results}

\section{Oil Paints}

A variety of unvarnished [6] and varnished oil paintings [5,9] have been treated to remove soot and char from fire exposure using atomic oxygen. All of the described paintings were able to be restored following treatment. The most challenging to clean was a painting of Mary Magdeline that was blistered in addition to being heavily soot covered from an arson fire at St. Alban's Episcopal church in Cleveland in June of 1989. The painting was treated using atomic oxygen for $230 \mathrm{hrs}$ to remove the soot and charred paint binder [9]. After cleaning, the paint pigment was loosely bound to the surface due to removal of the charred binder. With the guidance of conservators from the Cleveland Museum of Art, a fine spray mist of a Grumbacher non-yellowing resin based varnish for oils was applied to fix the pigment on the surface.

Afterward, an Acryloid F-10 ${ }^{\circledR}$ based picture varnish (Grumbacher) was applied to the surface by brush. Figure 1 shows the Mary Magdeline painting before and after atomic oxygen treatment. Removal of binder and addition of a substitute binder is typically only needed where there has been charring. For two oil paintings damaged in a fire at St. Stanislaus Church in Cleveland in 2002, their light soot damage was able to be cleaned without removing paint binder (Figure 2). The extent of cleaning is controlled by the treatment time. None of the paintings described here appeared to experience a shift in coloration as a result of exposure. Changes in coloration were also not observed for some modern paint formulations characterized using reflectance spectroscopy [10] but there are many that have not been tested. Only one of the oil paints treated to date, lead white, has been found to turn a brownish red upon exposure to atomic oxygen due to surface formation of lead oxide. Caution must be used when treating an untested paint medium using atomic oxygen if the cleaning will progress into the paint pigment.
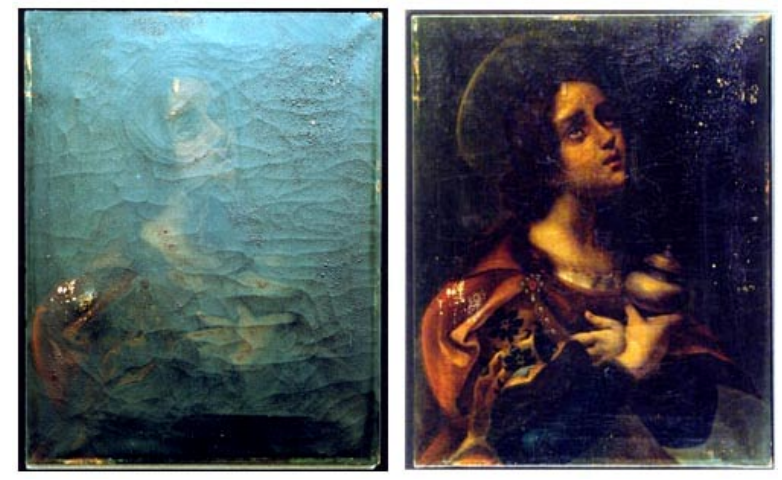

Figure 1.-Mary Magdeline oil painting with fire damage on the left and after atomic oxygen treatment for $230 \mathrm{hrs}$ and binder replacement on the right.
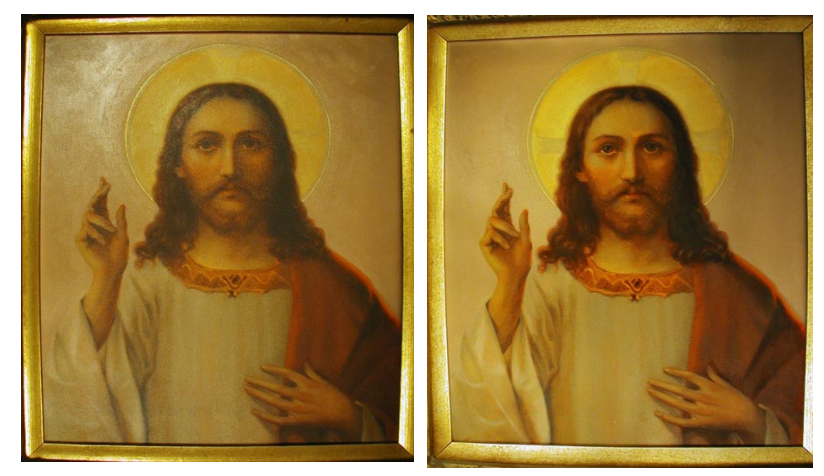

Figure 2.-Oil painting from St. Stanislaus Church with fire damage on the left and after atomic oxygen treatment for $7 \mathrm{hrs}$ on the right. 


\section{Acrylic Paints}

A variety of organic and inorganic acrylic paints (Heavy Body Carbon Black ${ }^{\circ}$, Heavy Body Hansa Yellow Medium ${ }^{\circ}$, Heavy Body Naphthol Red Light ${ }^{\circ}$, Heavy Body Pyrrole Orange ${ }^{\mathrm{o}}$, Heavy Body Burnt Sienna, Heavy Body Cadmium Yellow Medium, and Heavy Body Titanium White) (manufactured by Golden) on gesso provided by the Smithsonian Institution (SCRME) were exposed to soot from a simulated arson fire at the Cleveland Fire Department Training Facility as described in reference 11 . The soot covered panel was then treated using atomic oxygen. The panel contained stripes of acrylic paint both flat and impasto surrounded by unpainted gesso. Overall, the atomic oxygen appeared to be able to remove soot without disturbing the impasto regions (Figure 3). The organic pigmented paints, denoted by a superscript "o", however, experienced undesirable thinning due to loss of pigment when atomic oxygen had removed the soot and entered the paint. Because the panel, like many modern paintings, contained both thick impasto and flat thinly painted areas, there were a variety of levels of soot deposition (heavier at the top of the impasto features). This resulted in a surface that needed treatment to different durations of atomic oxygen exposure (ranging from 2 to $35 \mathrm{hrs}$ ). Surfaces like this may best be treated by short duration exposures to clean the thin areas and then masking these areas by painting with a sacrificial material, like a varnish, whose remaining portion can be easily removed after treatment of the whole has been concluded. Preliminary reflectance data taken with an AZ Technologies Laboratory Portable SpectroReflectometer (LPSR) indicates little change in the shape of the total reflectance curve for all of the paints except the Heavy Body Cadmium Yellow Medium which shows a slight blue shift after treatment. All of the paints experienced a visible loss in gloss, which is expected when a portion of the acrylic binder is removed. This can be reversed by application of the proper binder replacement material.

\section{Watercolors and Ink}

Stripes of six basic watercolors of a few centimeters in width were applied to half a sheet of standard watercolor paper (medium weight, acid free manufactured by Bienfang) and exposed in the same arson fire simulation as the acrylic paint panel for atomic oxygen treatment testing [11]. The colors are basic in the Cotman series manufactured by Winsor \& Newton (alizarin crimson, burnt sienna, lemon yellow, yellow ochre, cerulean blue and ultramarine blue). Reflectance was measured on each of the color stripes as a function of wavelength in the visible region (400 to $700 \mathrm{~nm}$ ) using the AZ Technologies LPSR prior to, after smoke exposure and after atomic oxygen treatment for $7 \mathrm{hrs}$. After treatment, the reflectance for burnt Sienna and yellow ochre returned to near the original levels, alizarin crimson and lemon yellow experienced a slight
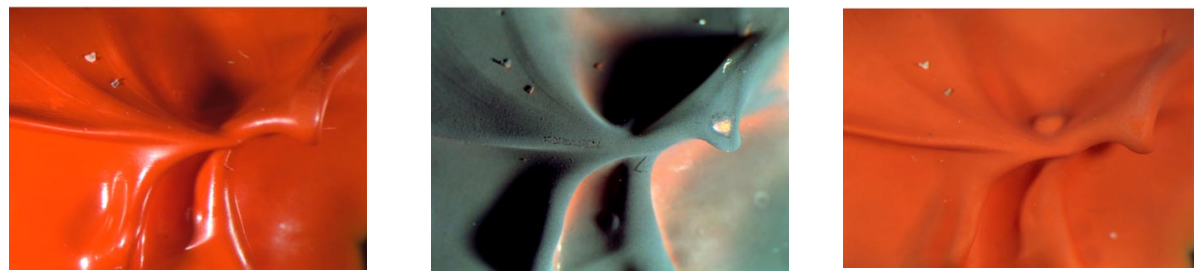

Figure 3.- Heavy Body Pyrrole Orange impasto area as received (left), after smoke exposure (center) and after atomic oxygen treatment $2.1 \mathrm{hrs}$ (right). 
bleaching, and ultramarine blue became very slightly redder [11]. The greatest change occurred for the cerulean blue, which experienced a green shift as a result of treatment. The results indicate that for some pigments, it is important to minimize the time that the pigment is exposed to atomic oxygen once the soot has been removed in order to prevent bleaching and changes in coloration [11].

Ink drawings and washes need to be treated for short duration and with caution as well since the pigments are mostly organic in nature. Atomic oxygen treatment of a smoke damaged and partially thermally decomposed Roy Lichtenstein ink on paper (untitled abstract from 1950) is described in reference 5. The Lichtenstein was able to be lightened but could not be fully restored due to yellowing of the paper from thermal damage and a need to stop treatment to prevent loss of too much of the ink pigment.

\section{Removal of Graffiti and Marks}

The ability to remove ink from a surface can be advantageous in the case of marks or graffiti on art works. Most inks, except for that from a black Sanford Sharpie ${ }^{\circledR}$ permanent marker were able to be removed from gesso, paper and canvas in 4.5 to 12 minutes as described in reference 12 using a pencil beam of atomic oxygen in air operated at atmospheric pressure. An erasure shield made from polymer sheet can reduce thinning of surrounding paper as the paper area not protected by ink can experience a slight thinning due to reaction with atomic oxygen.

In some cases, especially for porous media, it can be difficult to remove graffiti using solvents. In the case of an Andy Warhol painting at the Carnegie Museum of Art, a lipstick imprint on the surface of "Bathtub 1961" was unable to be removed using solvents because it would allow the lipstick oils to soak into the surface leaving a pink smudge [12]. At the invitation of conservators from the Carnegie Museum of Art, the atmospheric atomic oxygen beam source was transported to Pittsburgh and used on site to remove the lipstick smudge on the surface. Atomic oxygen treatment was performed by rastering the pencil beam over the smudge. The time required to fully remove it was approximately $5 \mathrm{hrs}$ and 25 minutes. The treatment is described in reference 12 . The resulting cleaned area was free of red pigment and oils from the lipstick, but was lighter and more diffusely reflecting than the rest of the painting. This was due to removal of some of the accumulated grime on the surface as well as a thin layer of the paint binder. Color matching restoration was performed by the conservator [12] and the painting was returned to display. Figure 4 contains comparison photos of the Andy Warhol painting before and after treatment.

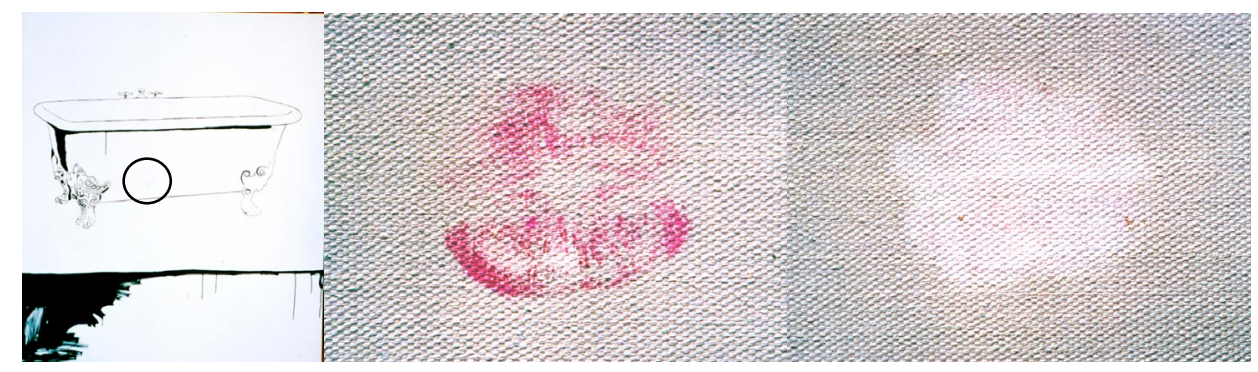

Figure 4.-Andy Warhol "Bathtub 1961" painting showing lipstick smudge in circled region (left) an enlarged view of the smudged area (center) and the same area after atomic oxygen treatment prior to color matching. 


\section{Textiles}

Samples of 100 percent cotton (red and white flag stripe), 100 percent wool (blue and magenta houndstooth), and 100 percent silk (floral print) were exposed in the Cleveland Fire Department training facility in a simulated arson fire described in reference 11 . The samples were half covered with a polymer sheet prior to atomic oxygen treatment in order to preserve one side as a control. Figure 5 shows the textiles after atomic oxygen treatment for $6.25 \mathrm{hrs}$. The treated sections of the cotton, wool and silk are facing the center of the photograph. The treatment removed most of the soot from the surface and restored the coloration of the wool and silk, but there was a slight bleaching of the red cotton after exposure as observed with the AZ Technologies LPSR. If treatment continues too long, the fabric will be weakened by thinning of the cellulosic fibers. Therefore there is a trade off between fully removing the soot and having an unbleached, strong fabric. With careful control of the treatment time, most of the soot could be safely removed from these types of fabrics.

A soot covered feather was also included for atomic oxygen treatment and can be seen in Figure 5 as well. As can be seen from the photo, the treated half of the feather is no longer remaining. Because the structure of a feather is intricate and fine, soot deposits are not uniform and there are areas of the feather that the atomic oxygen can reach and thin to its structural limit before the soot is removed. For this reason, atomic oxygen treatment is not recommended as a method to clean feathers.

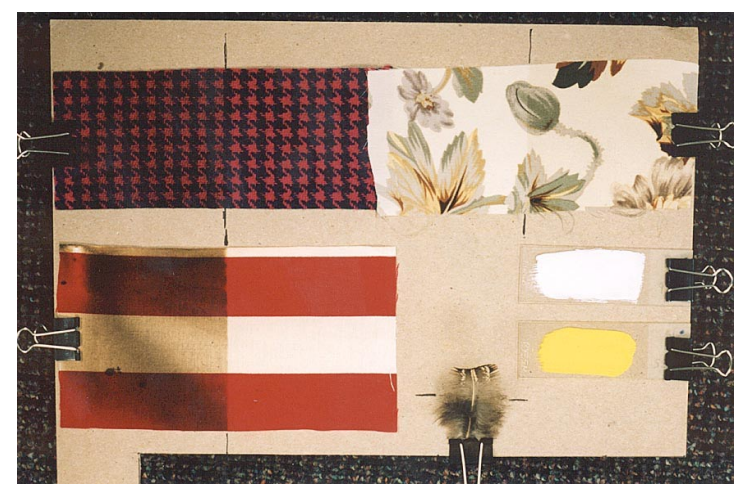

Figure 5.-Photograph of smoke exposed textiles after treatment of the central half of each with atomic oxygen.

\section{Conclusions and Cautions}

Atomic oxygen has been shown to be an effective technique for removal of char and soot as well as graffiti and ink marks from a variety of fire damaged media types. For all of the types of artist's media discussed here, however, caution must be used when treating an untested area using atomic oxygen if the cleaning will progress into the pigment or dyestuffs. A representative edge or corner that is typical of the whole should be treated first so that a determination can be made if the process is safe for the pigments or dyestuffs present. Organic pigments, dyestuffs and fibers will experience oxidation and removal so care must be taken to keep the treatment time as short as possible to minimize their loss. Treatment times should also be kept as short as possible to limit bleaching or changes in coloration for sensitive media. The technique is not intended to 
be a replacement for conventional restoration techniques, but may provide a valuable tool where conventional methods have not been effective enabling restoration of previously unrestorable works of art.

\section{References}

1. B.A. Banks, K.K. deGroh and S.K. Miller, "Low Earth Orbital Atomic Oxygen Interactions with Spacecraft Materials," Proceedings of the Fall MRS Conference, (Boston, MA, 2004), NASA/TM2004-213400.

2. B.A. Banks, S.K. Rutledge, "Low Earth Orbital Atomic Oxygen Simulation for Materials Durability Evaluation," Proceedings of the Fourth European Symposium on Spacecraft Materials in the Space Environment, (CERT, Toulouse, France, 1988), pp. 371-392.

3. B.A. Banks, S.K. Rutledge, P.E. Paulsen, and T.J. Stueber, "Simulation of Low Earth Orbital Atomic Oxygen Interaction with Materials by Means of an Oxygen Ion Beam," $18^{\text {th }}$ Annual Symposium on Applied Vacuum Science and Technology, (1989), NASA TM-101971.

4. C.S. Stidham, T.J. Stueber, B.A. Banks, J.A. Dever, S.K. Rutledge, "Low Earth Orbital Atomic Oxygen Environmental Simulation Facility for Space Materials Evaluation," $38^{\text {th }}$ International SAMPE Symposium and Exhibition, (Anaheim, CA, 1993), NASA TM-106128.

5. S. Rutledge, B. Banks, M. Forkapa, T. Stueber, E. Sechkar, and K. Malinowski, "Atomic Oxygen Treatment as a Method of Recovering Smoke-Damaged Paintings," Journal of the American Institute for Conservation of Historic and Artistic Works 39, (2000), pp. 65-74.

6. S.K. Rutledge and B.A. Banks, "Atomic Oxygen Treatment Technique for Removal of Smoke Damage from Paintings," MRS Fall Meeting, (Boston, MA, 1996), NASA TM-107403.

7. B.A. Banks, S.K. Rutledge, and M.J. Norris, "An Atmospheric Atomic Oxygen Source for Cleaning Smoke Damaged Art Objects," $26^{\text {th }}$ Annual Meeting of the American Institute for Conservation of Historic and Artistic Works, (Arlington, VA, 1998), NASA/TM-1998-208506.

8. U.S. Patent \#5,560,781, B.A. Banks and S.K. Rutledge, "Process for Non-Contact Removal of Organic Coatings from the Surface of Paintings, (1996).

9. S.K. Rutledge, B.A. Banks, V.A. Chichernea, "Recovery of a Charred Painting Using Atomic Oxygen Treatment," Proceedings of the $12^{\text {th }}$ Triennial Meeting of the International Committee for Conservation, ICOM, (Lyon, France, 1999), pp. 330-335.

10. S.K. Rutledge, B.A. Banks, M. Cales, "Atomic Oxygen Treatment for Non-Contact Removal of Organic Protective Coatings from Painting Surfaces, MRS Materials Issues in Art and Archaeology IV, (Cancun, Mexico, 1994), NASA TM-106650.

11. S.K. Rutledge, B.A. Banks, V.A. Chichernea, and C.A. Haytas, "Cleaning of Fire Damaged Watercolor and Textiles Using Atomic Oxygen," $18^{\text {th }}$ International Congress of the International Institute for Conservation of Historic and Artistic Works, IIC, (Melbourne, Australia, 2000), NASA/TM-2000-210335.

12. B.A. Banks, S.K. Rutledge, M. Karla, M.J. Norris, W. Real, C.A. Haytas, "Use of an Atmospheric Atomic Oxygen Beam for Restoration of Defaced Paintings," Proceedings of the $12^{\text {th }}$ Triennial Meeting of the International Committee for Conservation, ICOM, (Lyon, France, 1999), pp. 271-275. 


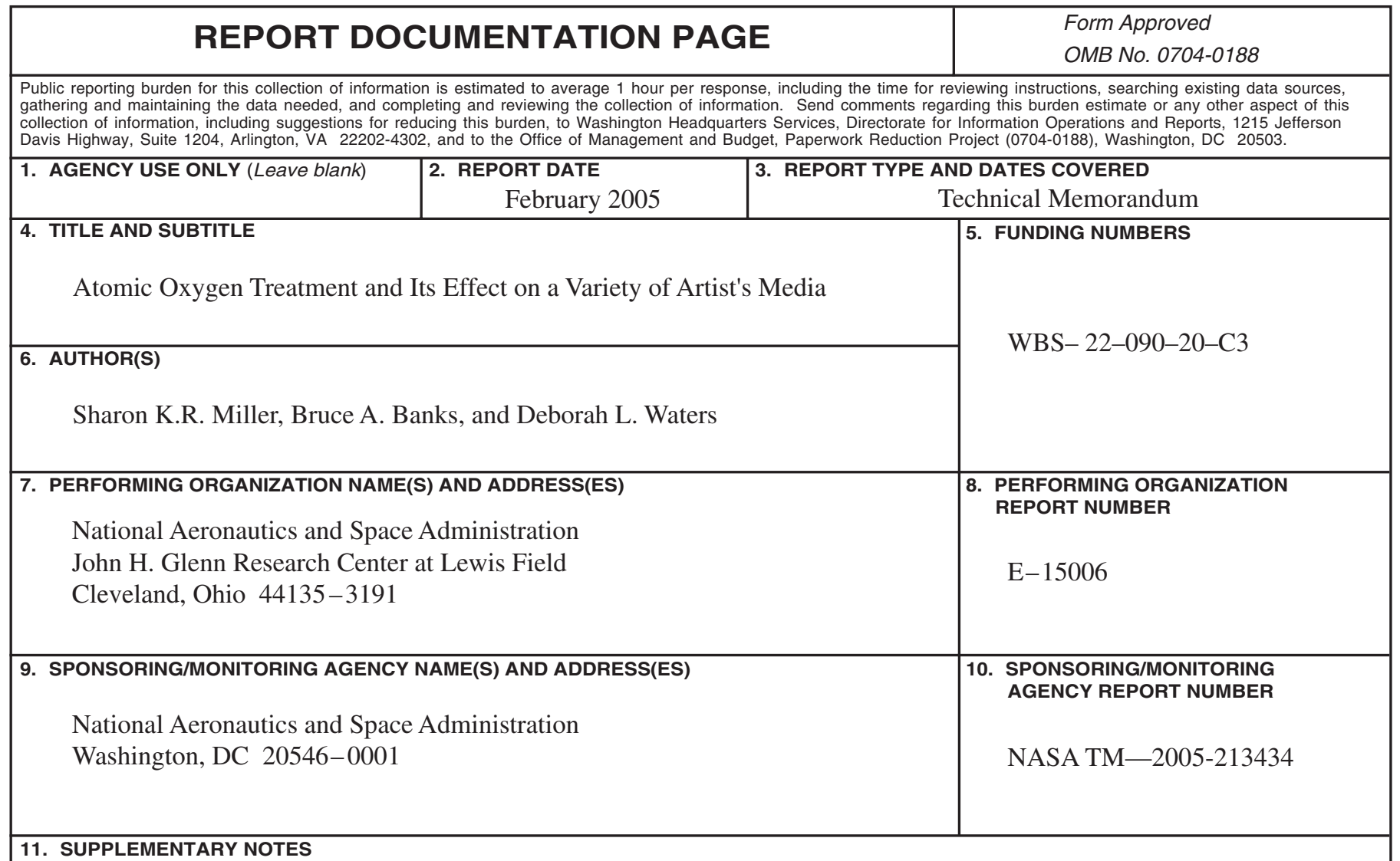

Prepared for the 2004 Fall Meeting sponsored by the Materials Research Society, Boston, Massachusetts, November 29December 3, 2004. Sharon K.R. Miller and Bruce A. Banks, NASA Glenn Research Center; Deborah L. Waters, QSS Group, Inc., 21000 Brookpark Road, Cleveland, Ohio 44135. Responsible person, Sharon K.R. Miller, organization code RPY, 216-433-2219.

\begin{tabular}{|l|l|l|l|l}
\hline 12a. DISTRIBUTION/AVAILABILITY STATEMENT & 12b. DISTRIBUTION CODE
\end{tabular}

Unclassified - Unlimited

Subject Category: 23

Available electronically at http://gltrs.grc.nasa.gov

This publication is available from the NASA Center for AeroSpace Information, 301-621-0390.

13. ABSTRACT (Maximum 200 words)

Atomic oxygen treatment has been investigated as an unconventional option for art restoration where conventional methods have not been effective. Exposure of surfaces to atomic oxygen was first performed to investigate the durability of materials in the low Earth orbit environment of space. The use of the ground based environmental simulation chambers, developed for atomic oxygen exposure testing, has been investigated in collaboration with conservators at a variety of institutions, as a method to clean the surfaces of works of art. The atomic oxygen treatment technique has been evaluated as a method to remove soot and char from the surface of oil paint (both varnished and unvarnished), watercolors, acrylic paint, and fabric as well as the removal of graffiti and other marks from surfaces which are too porous to lend themselves to conventional solvent removal techniques. This paper will discuss the treatment of these surfaces giving an example of each and a discussion of the treatment results.

14. SUBJECT TERMS 15. NUMBER OF PAGES

Atomic oxygen; Art restoration; Smoke damage; Watercolor; Oil paint; Acrylic paint; Ink; Graffiti; Textiles

17. SECURITY CLASSIFICATION OF REPORT

18. SECURITY CLASSIFICATION OF THIS PAGE

Unclassified

Unclassified

19. SECURITY CLASSIFICATION OF ABSTRACT

Unclassified 

